\title{
Louis Kunkel
}

The 2009 March of Dimes Prize in Developmental Biology has been awarded jointly to Kevin Campbell of the University of lowa and to Louis Kunkel of Harvard Medical School and The Children's Hospital, Boston,

for their pioneering work in identifying the genes and proteins that are disrupted in muscular dystrophies. The prize recognizes researchers whose work has contributed to our understanding of the science that underlies birth defects. We talked to the winners about their scientific careers and their views on biomedical research. This month's interview is with Louis Kunkel, who spoke to Tanita Casci. The interview with Kevin Campbell appeared in our June issue.

\section{What drew you to work on muscular} dystrophy [MD]?

I had been at UCSF working with Drosophila. That didn't go too well so I came back to Boston to do a fellowship with the late Sam Latt; he said he would support me for a year but after that I would need to find my own support. We were going to work on the $\mathrm{X}$ chromosome, so we thought "why don't we propose that we can map the Duchenne muscular dystrophy [DMD] gene with the markers we are going to generate?" So I applied to the MDA [the Muscular Dystrophy Association] for a fellowship, and they gave it to me. Initially what motivated me to work on MD was that I needed a fellowship. I've subsequently been supported by the MDA on and off over the years, and I am now the chair of their scientific advisory committee.

\section{So the MDA took a gamble with you?}

Well, they didn't gamble too much. What they did is have three or four groups competing on the same project. We actually shared expertise with these competitor labs, and talked a lot. The MDA sort of fostered that collaborative effort. We served as the 'predecessor' to those large collaborative studies that would be done for cystic fibrosis or Huntington's disease.

\section{Large-scale collaborations continue to be crucial in medical genetics.}

Yes, absolutely. Data sharing in DMD was spearheaded by Kate Bushby, who has done a wonderful job in coordinating the patient registry throughout Europe, and set the model for what is happening in the US. Mutation-specific therapies are coming online, and it's going to be vitally important to identify cohorts of patients to whom a particular therapy can be applied.

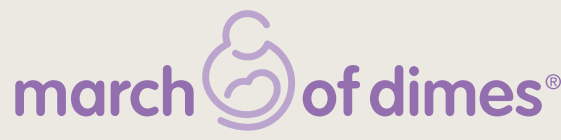

What are the prospects of a child born today with DMD compared with 20 years ago?

The biggest thing has been the development of portable respirators - which increase lifespan by at least 10 years. But improved diagnostics has also been very important. We have kids who know they don't produce any dystrophin protein but don't know why because their gene was never sequenced - that now needs to be done. This information, which will soon be available cheaply using high-throughout sequencing, is more than just a diagnosis; it will inform therapies.

\section{Which therapies hold most promise?}

There are two prominent therapies for DMD right now, both of them in trial. One is exon skipping and the other is stop-codon read-through. In both cases you need to know the nature of the mutation. These approaches are going to ameliorate symptoms, but they are not going to cure the disease. My guess is that stem cell-based therapies may go further than that — but they are a long way away.

\section{What is human disease genetics going to look} like in the future?

You're going to be able to sequence everybody's genome. To understand what that sequence means for any one individual, you're going to need huge cohorts of people, followed over time to allow you to tease out what the sequence means. We've just received IRB [institutional review board] approval to pilot a new project to recruit patients in large-scale genome-wide studies. The only way to get that number of people involved is to make a change in how health care is carried out [...] to a system where people are participating in the research and letting a DNA sample be utilized and their clinical information be longitudinally updated.
What's in it for patients?

The beauty of this system is that we can communicate back to the patient via the genetics without knowing who they are. They will have their genetics in a personally held, controlled health record (just like your credit card) and every time you plug that into the hospital you can update an anonymized database, which also has the genetic data. This allows you to analyze the data and say: "Ah, this group of individuals has this variant that strongly puts them at risk for something." You can contact those people and ask them to come back to the study - all through the genetics.

\section{Such information has to be communicated appropriately.}

An independent board looks at the relevance of what you're sending. In a genome-wide association study cohort of 50,000 women there might be 10 carriers of a $D M D$ mutation. We should be communicating information like this, about things that we can do something about. This is true of a whole lot of incidental findings.

\section{How has human genetics changed over your career?}

My postdoc Michel Koenig sequenced $14 \mathrm{~kb}$ of [the $D M D$ ] cDNA manually, on gels, read those gels and manually entered the data into the computer. It took him 6 months to sequence that. Today you can do hundreds at a time and send them off to a facility and get a file back that you can download and read. Molecular diagnostics are now a major tool in medicine - that wasn't there 20 years ago.

\section{How is the next generation of geneticists being trained?}

This is a very difficult time for young scientists. I think that more should be done to help these young people. It would be great to offer them a competition for a sum of money that wasn't reliant on them having preliminary data but on their potential. A lot of young people are not willing to take risks. I took a big risk in attempting to clone the Duchenne gene, and was prepared to stake my whole career on it. If I had been scooped on it, I'd have spent 3 years working and not be recognized for what we did. 